Article

\title{
Fine-Scale Sea Ice Structure Characterized Using Underwater Acoustic Methods
}

\author{
Vanessa Lucieer ${ }^{1,2, *}$, Amy W. Nau ${ }^{1,3}$, Alexander L. Forrest ${ }^{2,4}$ and Ian Hawes ${ }^{5}$ \\ 1 Institute for Marine and Antarctic Studies, University of Tasmania, Tasmania 7000, Australia; \\ Amy.Nau@csiro.au \\ 2 Australian Maritime College, University of Tasmania, Tasmania 7250, Australia; alforrest@ucdavis.edu \\ 3 Commonwealth Scientific and Industrial Research Organisation (CSIRO), Hobart, Tasmania 7000, Australia \\ 4 Civil and Environmental Engineering, University of California, Davis, CA 95616, USA \\ 5 Gateway Antarctica, University of Canterbury, Christchurch 4800, New Zealand; \\ ian.hawes@canterbury.ac.nz \\ * Correspondence: vanessa.lucieer@utas.edu.au; Tel.: +61-3-6226-6931
}

Academic Editors: Nicholas Makris, Xiaofeng Li and Prasad S. Thenkabail

Received: 30 June 2016; Accepted: 24 September 2016; Published: 5 October 2016

\begin{abstract}
Antarctic sea ice is known to provide unique ecosystem habitat at the ice-ocean interface. Mapping sea ice characteristics-such as thickness and roughness-at high resolution from beneath the ice is difficult due to access. A Geoswath Plus phase-measuring bathymetric sonar mounted on an autonomous underwater vehicle (AUV) was employed in this study to collect data underneath the sea ice at Cape Evans in Antarctica in November 2014. This study demonstrates how acoustic data can be collected and processed to resolutions of $1 \mathrm{~m}$ for acoustic bathymetry and $5 \mathrm{~cm}$ for acoustic backscatter in this challenging environment. Different ice textures such as platelet ice, smooth ice, and sea ice morphologies, ranging in size from 1 to $50 \mathrm{~m}$ were characterized. The acoustic techniques developed in this work could provide a key to understanding the distribution of sea ice communities, as they are nondisruptive to the fragile ice environments and provide geolocated data over large spatial extents. These results improve our understanding of sea ice properties and the complex, highly variable ecosystem that exists at this boundary.
\end{abstract}

Keywords: sea ice; autonomous underwater vehicles; multibeam acoustic data; underwater acoustic processing methods

\section{Introduction}

Autonomous underwater vehicles (AUVs) have been used in the Arctic since the 1970s, and increasingly in the Antarctic in recent years, to acoustically survey the geometric properties of the underside surface of sea ice [1-5]. There are various motivations that have initiated this research, including mapping sea ice thickness [6]; describing the roughness characteristics of the ice to determine wind and water drag coefficients for dynamical modeling [7]; and monitoring the transition of multiyear sea ice to first year sea ice [8]. Sea ice is one of the defining components of the polar marine environment in either hemisphere, and primary productivity associated with sea ice is vital to biological systems [9]. Over the annual cycle, once surface sunlight levels rise and light penetration increases as a result of a thinning snow pack, algae begins to grow on the underside of the sea ice and these algae support a complex system of herbivores at the bottom of the food chain [10,11]. It has been estimated that ice algae contribute $20 \%$ of primary production in some polar regions, at a time when few other resources are available [12,13]. Fine-scale acoustic data ( $\mathrm{cm}$ resolution) can broaden our understanding of these complex ecosystems and can allow multidisciplinary questions to be asked (e.g., spanning biology, ecology, physics, etc.) where data are required at a resolution commensurate with the associated small spatial and temporal scale processes. 
Polar fast ice is not a uniform medium, and in many localities any semblance of a smooth, flat underside is compromised by the presence of platelet ice (disk-shaped ice crystals). Platelet ice tends to be found close to ice shelves, and is thought to originate from supercooled water emerging from under these structures; it is most common in Antarctica, though it does occur in the Arctic [14,15]. Platelets can form layers of unconsolidated "slush" under sea ice, from centimeters to meters thick [16,17] or can be incorporated into the growing ice matrix [18-20]. Where platelets are incorporated into ice, they initially form a complex 3-dimensional habitat extending into the water. This partially isolated microzone is disproportionally productive compared to underlying pelagic habitat, is colonized by ice algae [10] and invertebrates [21], and is recognized as an important nursery area for the Antarctic silverfish Pleurogramma antarcticum [22]. P. antarcticum is a keystone species in Antarctica, representing the primary food species of many mammals, birds and other fishes [23].

Ice algae are patchy and easily disrupted, and the traditional sampling methods based on ice coring struggle to quantify biomass on more than very local scales (point-by-point). With the need for better tools to map sea ice algae, we trialed an autonomous underwater vehicle at Cape Evans in Antarctica. Previous studies generated evidence to suggest that the rough texture of the bottom of the ice sheets is essential for the algae to grow [24]. Ice platelets that protrude up to $10 \mathrm{~cm}$ from the bottom of the sea ice allow small clumps of algae to wedge themselves between these protruding platelets [25]. At present, quantification of these productive and potentially ecologically significant sea ice habitats is dependent on laborious and spatially constrained coring approaches. Development of robust, remote techniques would allow broad-scale mapping and monitoring programs to be undertaken.

To better understand and quantify algal distribution and the factors controlling their dynamics (including light availability) information is required on sea ice thickness, ice structure, and ice surface morphologies. All of these ice characteristics interplay in a complex way to affect light properties reaching the underside of the sea ice [26]. The challenges with measuring light availability to algae under the sea ice include light being attenuated through the ice. This can be caused by a wide variety of factors, some of which can be quantified, such as snow on the ice surface where its thickness and distribution which can be mapped using unmanned aerial vehicles (UAVs) [27]. Other factors such as sea ice structure and ice texture have not been able to be quantified at resolutions relevant to point measurements of light (less than $1 \mathrm{~m}$ ) until now.

The use of multibeam sonars on board AUVs is becoming an increasingly well-established practice under a variety of ice regimes. While ice shelves and floating glacier tongues have drawn international attention (e.g., [5,28]), there have been significant advances in mapping water column properties (e.g., [29] and sea ice thicknesses using these smaller AUVs (e.g., [30])). Smaller vehicles allow for more versatility in the deployments from both landfast ice [31] and drifting ice [6]. To date, the majority of AUV under-ice deployments have been in the Arctic; however, there is an increasing interest in using these platforms in the Antarctic as the technology becomes more robust. The particular focus on these deployments has been higher-resolution mapping of these under-ice environments that are difficult to access by any other means.

The research presented in this paper will discuss a new method for the spatial and textural analysis of fine-scale acoustic data of sea ice collected with an upward configured Geoswath Plus phase-measuring bathymetric sonar mounted on a Teledyne Gavia AUV. We present multiple workflows for acoustic processing of both the bathymetry and backscatter data. These novel methods reveal, for the first time, characteristic acoustic signatures of different ice surfaces such as platelet ice, smooth ice, and ice features (brine drainage channels and ice keels) over small $(1 \mathrm{~m})$ and large scales $(>50 \mathrm{~m})$. These results present a significant advancement in our understanding of this system where traditional remote sensing techniques are limited by the presence of ice cover. 


\section{Materials and Methods}

\subsection{Site Location}

Between 4 and 7 November 2014, an AUV survey was conducted at Cape Evans, Antarctica (Figure 1). The survey area covered $12.42 \mathrm{ha}\left(0.124 \mathrm{~km}^{2}\right)$ under the sea ice. Cape Evans was selected as the survey region for two reasons. Firstly, it has a near-annual sea ice breakout that would ensure the presence of relatively thin ice that would be moderately easy to deploy an AUV through. Secondly, it has previously been found to be a boundary between ice with and without platelets, such that a degree of habitat variability could be expected [18] that would facilitate testing of remote sensing technologies.
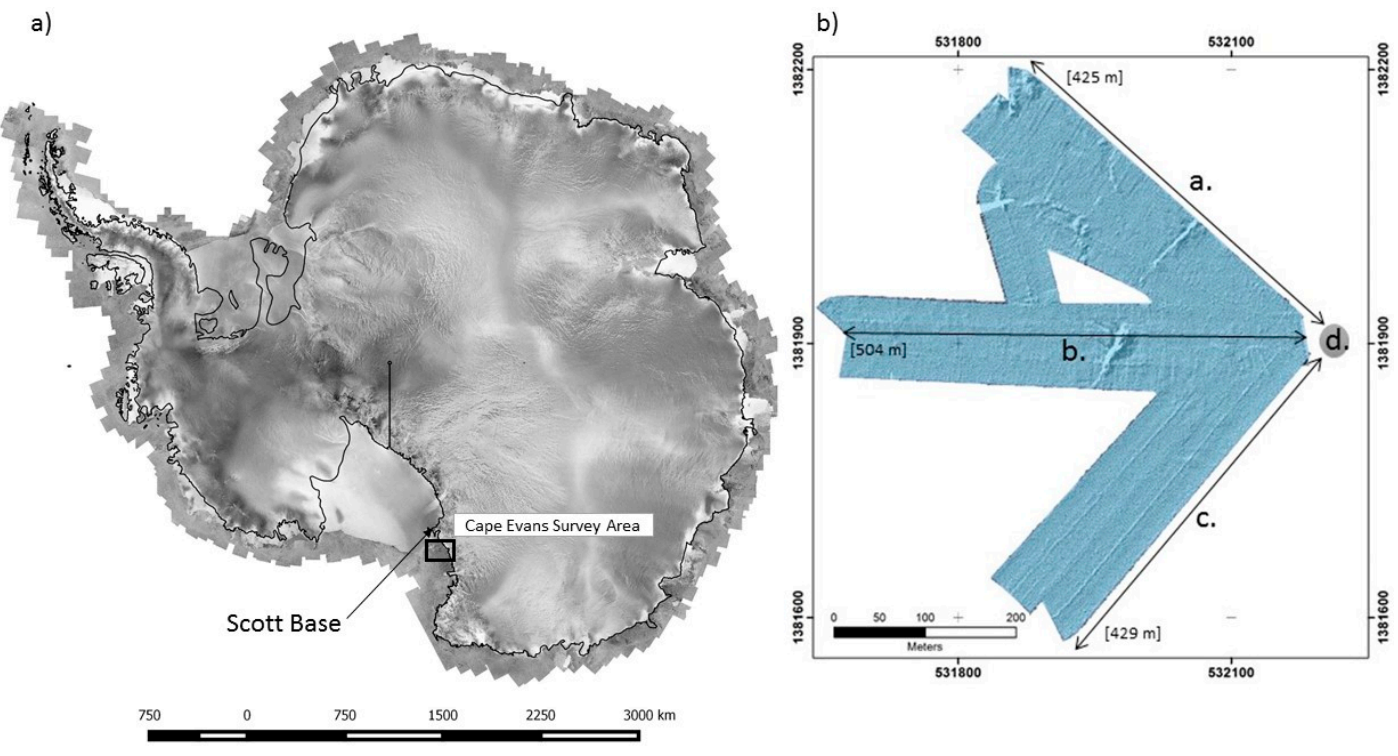

Figure 1. (a) Location of the autonomous underwater vehicle (AUV) survey site at Cape Evans, Antarctica; (b) length and configuration of the three primary AUV survey lines $\mathrm{a} / \mathrm{b} / \mathrm{c}$ and the deployment hole location $\mathrm{d}$.

\subsection{Acoustic Data Acquisition and Processing}

\subsubsection{Data Acquisition and Configuration of the AUV}

The underside of the sea ice at Cape Evans on the Ross Sea was mapped using a Geoswath Plus $500 \mathrm{Khz}$ phase-measuring bathymetric sonar mounted on a Teledyne Gavia AUV. As configured, this vehicle was $2.7 \mathrm{~m}$ long and $0.2 \mathrm{~m}$ in diameter. The Geoswath Plus transducers were mounted 180 degrees from the normal bathymetric configuration to make measurements of the sea ice rather than the sea floor (Figure 2). The transducers were located fore of the pivot point of the vehicle but as near to the inertial motion unit of the vehicle in order to provide the best roll, pitch, and yaw correction as possible in post-processing. Data were collected over 11 surveys that were conducted from a single point of origin (Figure 1b) from a hole in the sea ice where the AUV was deployed (-77:38:09, 166:20:34). Although the AUV was being operated on a tether for safety purposes, the AUV was programmed to maintain a constant distance of $6-8 \mathrm{~m}$ from the sea ice surface. This generated a swath width of $50 \mathrm{~m}$ wide. The total length of transect a was $425 \mathrm{~m}$, transect b was $504 \mathrm{~m}$, and transect c was 429 m (Figure 1b).

\subsubsection{Bathymetric (Depth) Data Processing}

The Geoswath Plus acoustic measurements were initially processed using CARIS (Hips and Sips version 8.1) software. CARIS is a commercial off-the-shelf software package that is used for acoustic data processing. A vehicle-specific vessel file was initially created in the workflow to represent the 180 degree inverted configuration of the transducers on the AUV. This must be created to account for 
the specific transducer installations for each AUV. This allowed the inverted nature of the data to be corrected for and to properly calculate the offsets based on the AUV depth. This was required as CARIS vessel files do not have a sensor setup to input offsets with reference to the pressure depth sensor.

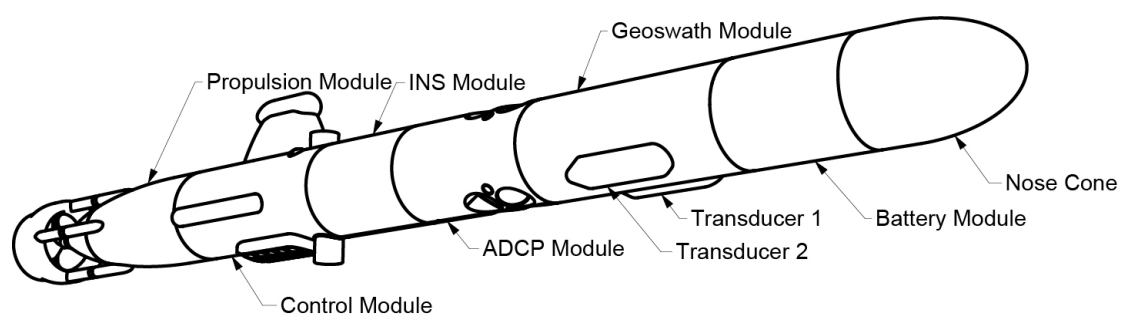

Figure 2. The specification of the Gavia AUV with the Geoswath Plus module and transducer configuration.

Processing data for an upward-looking sonar introduces complications that are not present in a typical bathymetric survey, so several processing methods were tested to develop an optimum workflow (Figure 3). The end product of this workflow is a surface representing the ice thickness.

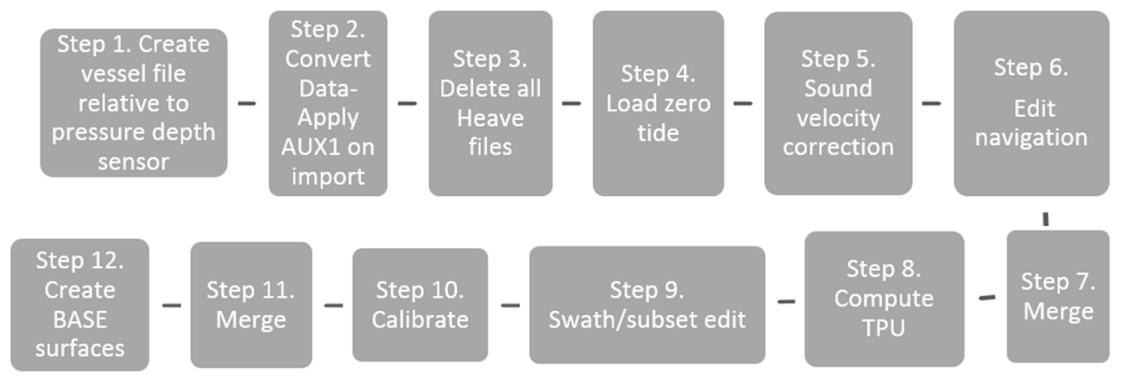

Figure 3. Processing workflow for under ice acoustic bathymetry processing. Step 2 AUX1 relates to the pressure based depth values.

Geoswath data are typically collected as raw data format (.RDF) files which contain information on the navigation and attitude of the vessel, data for each sonar ping, and AUV depth generated from the pressure-based depth sensor. In order to calculate the correct depth relative to the AUV depth, the pressure-based depth sensor needed to be used as the reference point, rather than the center point of the vessel, which is the default configuration for Teledyne Gavia. To correct for this, the $X, Y$, and $Z$ offsets for each transducer were corrected to the location of the pressure-based depth sensor based on measured values provided in the original vessel file and from offsets to the pressure sensor on the vehicle itself.

The heave sensor was set not to "apply heave values" in step three. A zero tide file was loaded to all lines. No tidal corrections were applied, as it was determined that the depth from the pressure sensor would compensate for depth relative to the ice surface, which was also being tidally modulated.

Applying correct "sound velocity profiles" (SVP) is a critical step for processing Geoswath Plus data since SVP is not applied on acquisition and must be corrected for based on the angles of the transducer setup. A sound velocity profile was created based on a sound velocity cast performed at the site using an RBR Concerto CTD logger. The cast was performed on November 8 and provided a surface sound velocity value of $1449 \mathrm{~m} / \mathrm{s}$. Several SVPs based on this data were tested, and it was determined that using a constant profile of $1449 \mathrm{~m} / \mathrm{s}$ was the best option to minimize bending in the outer beams and create an even surface. Since the survey is inverted, the next best option was to invert the first $10 \mathrm{~m}$ of the SVP, which forces CARIS to apply SV values for inverted depth. Depths at $1 \mathrm{~m}$ and $100 \mathrm{~m}$ were set to values of $1449.0 \mathrm{~m} / \mathrm{s}$ to create a constant profile, which was then applied to all lines. Navigation was reviewed in the Navigation Editor of CARIS and outliers were removed with interpolation. 
The merge function converts all of the raw data to HIPS format with the corrections from the previous steps (converting data, adding pressure-based depth, deleting the heave values, loading the zero tide, applying the sound velocity corrections, editing the navigation file) and produces a file that is ready for the calculation of total propagated uncertainty and generation into a gridded surface.

Total propagated uncertainty (TPU) was calculated for all lines using the offset values provided in the vessel file. TPU offsets were set to represent the angle at which the transducers were mounted on the AUV. Generally, this is +60 for Transducer 1 and -60 for Transducer 2 . These angles must also be set as Roll values for SVP1 and SVP2, respectively, in order to ensure proper refraction corrections when the sound velocity profile is applied. Offsets for SVP1 and SVP2 were automatically set based on the Transducer 1 and Transducer 2 offsets.

\subsubsection{Data Corrections and Cleaning}

After all corrections were applied, data were cleaned using Swath Editor. Due to the nature of interferometric sonars, the Geoswath Plus system provides very dense point data, but can be very noisy, particularly around nadir where phase angles are difficult to distinguish. Most processing methods for interferometric data involve using preliminary filters to reduce the number of points before processing. Since there were only 11 lines in this project, it was decided not to use filters on import to ensure that all details in the data were preserved. This resulted in a large number of points that had to be rejected, but typically the noise was in a characteristic pattern which made it easy to identify and clean. There was a large pitch artefact on the turn at the start of line $C$ that was minimized by manual cleaning, which is still slightly visible in the final surfaces, but this did not prevent subtle surface features from being identified.

\subsubsection{Calibration}

There is a large distinguishable feature ( $\sim \mathrm{m}$ thick) within the survey region on the center east-west lines which was primarily used to align and calibrate the data. During initial processing using the original Hips Vessel File (HVF), with roll equal to zero, this resulted in two similar features on the edges of these lines. However, it was discovered that applying the 180 degree rotation to roll to invert the data would result in a single seamless feature along the middle of these lines, as well as to orient the data so that pressure depth values (AUX1) would be properly applied on import. Additional small features were used to validate this, and were also found to match if the roll was inverted. Based on this, it was assumed that the transducer configuration had not been inverted on acquisition; therefore, the 180 degree roll would need to be applied to result in the proper positions for the port and starboard beams for each transducer. Before performing calibrations, the values for both transducers in the vessel file were set to Roll $=180$, Pitch $=0$, and Yaw $=0$. Calibrations for pitch and roll were then performed using the four southern overlapping survey lines (lines 110610361, 110610425, 110623430, and 110623493). Roll values were determined as 0.2 for Transducer 1 and 1.0 for Transducer 2 . These values were updated in the vessel file by adding them to the 180 degree roll offset (180.2 and 181, respectively). Pitch was determined to be 0 for both transducers. Lines 11076404 and 11076481 were used to calibrate yaw, and a 5 degree yaw offset was added to both transducers.

\subsection{Establishing a Geoswath Processing Workflow for AUV Operations}

The workflow utilized in this analysis allowed CARIS to deal with the inverted nature of the data and properly calculate offsets based on AUV depth. AUV depth is measured by a pressure-based depth sensor incorporated into the vehicle architecture. The current version of CARIS does not have a sensor setup in the vessel file to input offsets to the pressure-based depth sensor. This means that in order to calculate the correct depths relative to the AUV depth, the pressure-based depth sensor needs to be used as the reference point, rather than the center point of the vessel, which is the default vessel configuration for Gavia. To correct for this, the X, Y, and Z offsets for each transducer were corrected to the location of the pressure-based depth sensor based on measured values provided in the original vessel file and from offsets to the pressure sensor (Figure 4). 


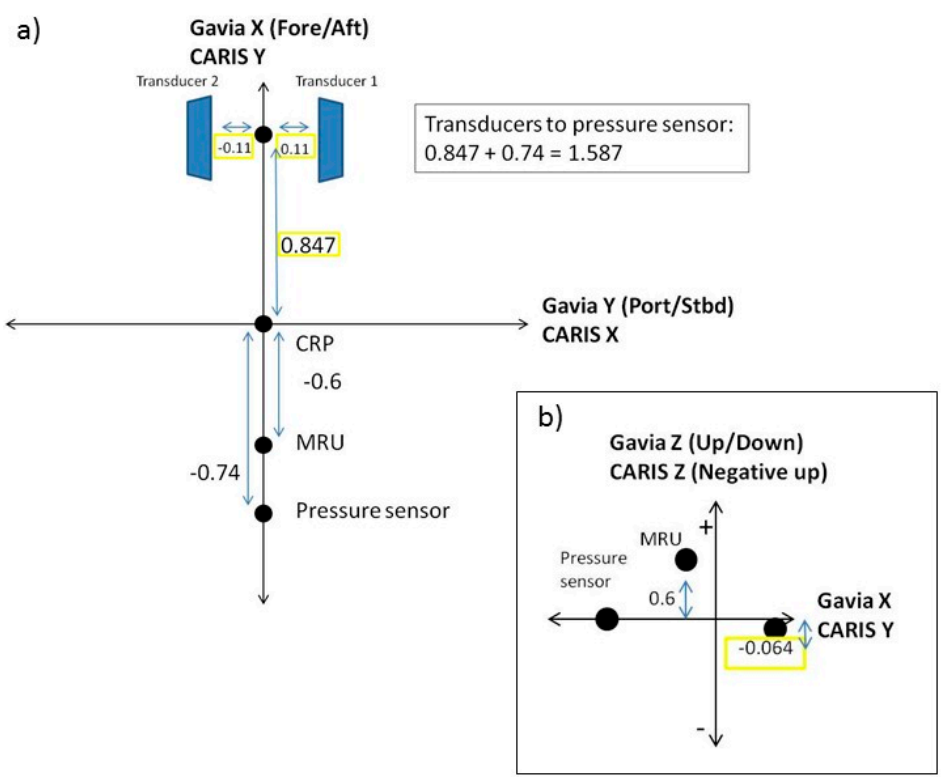

Figure 4. This figure shows the offsets determined from the CARIS and Gavia orientation conventions. The values highlighted in yellow were values provided in the original vessel file. All other values were taken from the Gavia Operations Manual [32]; (a) shows the orientation of the vehicle in top down dimension and (b) shows the vehicle in cross-section. All units are in meters.

The heave sensor was set not to apply heave values. TPU offsets were kept from the original offsets from the motion reference unit (MRU) to the transducers and Trans Roll values were set to represent the angle at which the transducers were mounted on the AUV. Generally, this is +60 for Transducer 1 and -60 for Transducer 2. These angles must also be set as Roll values for SVP1 and SVP2 in order to ensure proper refraction corrections when sound velocity is applied. Roll values were set to 60 degree for SVP1 and -60 for SVP2. Offsets for SVP1 and SVP2 were automatically set based on the Transducer 1 and Transducer 2 offsets.

\subsection{Backscatter Data Processing}

The second product generated by the Geoswath Plus, in addition to bathymetric data is acoustic backscatter. A separate HVF was created to process the backscatter data since motion correction values (roll, pitch, yaw) within the Transducer sensor offsets in the HVF are not applied to backscatter. To invert the backscatter imagery, a 180 degree Gyro error at 0 degrees was added to the vessel file. Data were imported with this vessel file using the same steps as for the bathymetry data. Side Scan Editor (a tool in CARIS for viewing and editing backscatter data) was used to determine the best settings to be applied to the backscatter data (Figure 5).

A height offset of $7 \mathrm{~m}$ was applied to compensate for the average altitude of the AUV from the ice surface in order to close gaps in the backscatter data near nadir. Time varied gain (TVG) by a factor of 10 was applied to both sides and gain was set to none. A beam pattern correction was created using all lines and this correction was applied to both port and starboard sides. Despeckling was not performed so as to preserve the small features visible within the backscatter imagery. These settings minimized artefacts at nadir due to the altitude of the AUV, although the darker patches around nadir on some lines could not be fully removed. Backscatter data were then processed using the CARIS Mosaic Editor SIPS Side Scan engine. Georeferenced Backscatter Rasters (GeoBaRs) were created for each line at resolutions of $5 \mathrm{~cm}$ and $1 \mathrm{~m}$. The gain was normalized between the GeoBaRs for each resolution set, and these were then used to create backscatter mosaics. The workflow for processing the backscatter is summarized in Figure 5. 
Final mosaics were exported as GeoTiffs at resolutions of $5 \mathrm{~cm}$ and $1 \mathrm{~m}$. The intensity range for all backscatter images was 0-70 dB. ASCII files (comma delimited) were also exported from the mosaics as X, Y, Intensity values. The X and Y coordinates are in WGS84 UTM zone 58S (meters).

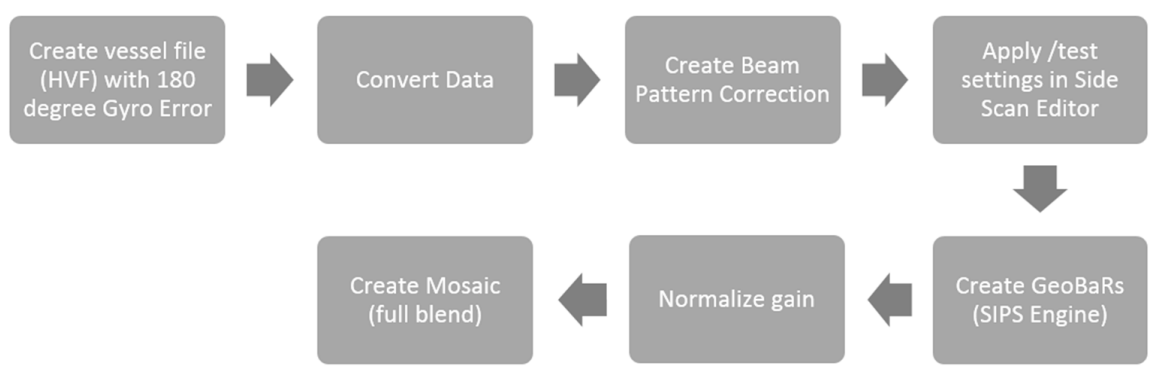

Figure 5. Processing workflow for under ice acoustic backscatter processing.

\subsection{Sea Ice Morphology Spatial Analysis and Image Processing}

The bathymetric surface (representing the sea ice thickness) was analyzed in ArcGIS 10.1.2 using the spatial analyst tools and the Benthic Terrain Modeler extension. Spatial metrics of slope and vector ruggedness measure (VRM) were calculated.

The multibeam backscatter surface was processed using ECognition, an image classification software produced by Trimble. In this analysis, an object-based nearest neighbor classification (NN classification) is applied to identify difference ice textures based on the acoustic differences in $\mathrm{dB}$ from the $\mathrm{dB}$ backscatter differences. The nearest neighbor classification applies statistics to separate classes based on regions of interest (ROIs) from field validation data. The acoustic backscatter image was processed as per the methods outlined in $[33,34]$. The image validation data from a remotely operated vehicle (ROV) Section 2.6 was used to identify two different ice classes: (1) platelet ice and (2) smooth ice.

In this research, we segment the image based on criteria of scale [ 200]. This is a unitless number that defines the spatial resolution of the multiresolution segmentation. A higher value will create larger image objects. The shape criterion was set to 0.5 [range $0-1$ ]. The larger the number the more value will be placed on color during the segmentation. The compactness criterion was set to 0.1 [range 0-1]. A higher compactness criterion value means the more bound (circular) an object will be in the segmentation process. In this process, we seek to create image objects with the largest scale (highest homogeneity) that are still able to discern between different textural boundaries.

Statistics were calculated from the ROI segments. The statistics chosen for differentiating the ice textures included: grey-level co-occurrence matrix (GLCM) homogeneity, GLCM contrast, GLCM standard deviation, GLCM dissimilarity, GLCM mean, backscatter intensity mean (dB), and standard deviation of $\mathrm{dB}$. The classification process classifies all objects in the entire image based on the selected samples and the defined statistics. It will classify each object based on its "closeness" to the ROI segments. Statistics that fell outside of the platelet or smooth ice ROI were labeled as unclassified.

\subsection{Image Validation}

The different ice surfaces identified by both the sea ice morphology analysis and the sea ice textural analysis were validated using an ROV. The ROV employed was a Seabotix LBV 150 with a wide dynamic range color camera system. Coupled to the color camera is a high intensity LED array providing bright white light throughout the 270 degree range of view. Nine ROV surveys were conducted between 3 and 5 November 2014. The ROV was deployed through the same ice hole as the AUV. The compass on board the ROV was used to spatially reference the images relative to the survey path of the AUV within a $10 \mathrm{~m}$ radius of the deployment hole. This meant that the representative images of the different ice textures could be spatially estimated in the video transect by referencing to the ice hole visible in the footage. 


\subsection{Ice Thickness Validation}

The ice thickness measurements were validated using ice core data collected at 14 locations over the field site. The ice cores were sampled with a $90 \mathrm{~mm}$ diameter Kovacs ice corer. The ice cores were taken primarily for a biological campaign but were made available to this study for field validation. The location of the ice cores was recorded with a Garmin GPS unit.

\section{Results}

\subsection{Sea Ice Morphology}

From the sea ice, thickness surface morphologies of the sea ice could be generated. The "underside surface" of the sea ice morphology was characterized by slope and vector ruggedness (Figure 6).
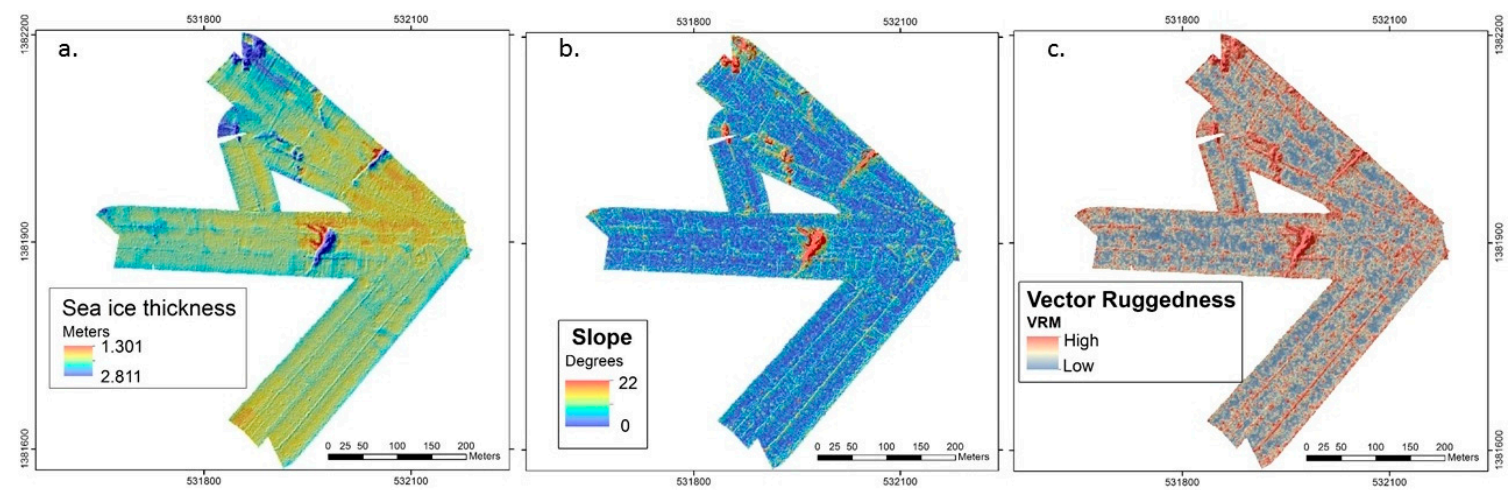

Figure 6. Spatial metrics that were derived from the $1 \mathrm{~m}$ bathymetric grid; (a) sea ice thickness; (b) slope [35]; (c) vector ruggedness measure (VRM).

\subsubsection{Sea Ice Thickness}

Pressure depth values represent the AUV depth calculated from a pressure sensor mounted on the AUV. For a typical bathymetric AUV survey, applying pressure depth values would add the AUV depth (AUV to sea surface) to the raw ping depth (as in the distance of the ship or AUV transducers to the seabed), which would then provide the true depth from the seafloor to the water surface. For an inverted survey such as this, the ping depth should instead be subtracted from the pressure depth values to compensate for variations in the AUV depth below the ice surface and provide an estimation of ice thickness below sea level (Figure 7). With the vessel file flipped using the 180 degree offsets for roll, applying pressure depth values when importing into CARIS corrects for the depth of the AUV below the ice in the correct direction. Sea ice thickness is shown in Figure 6a and ranged from $1.3 \mathrm{~m}$ to $2.8 \mathrm{~m}$.

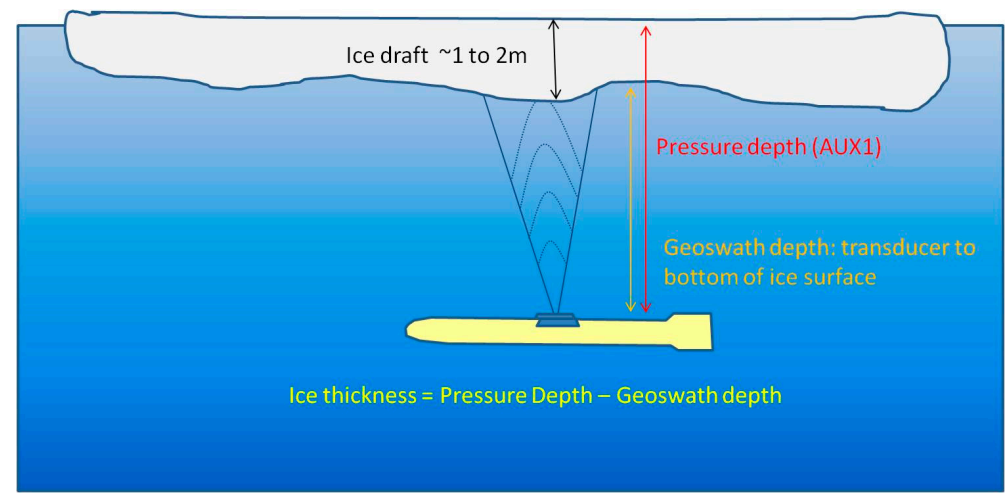

Figure 7. Concept diagram of the ice thickness calculation based on AUV depth. 
To validate the sea ice thickness surface, we compare the results with ice cores taken over the survey site (Figure 8). In Table 1 we show the comparison of the results of the ice thickness from both the pressure sensor on the AUV and the ice corer. The average variation was $11.31 \mathrm{~cm}$ across the 14 samples. The range of difference values was from $10 \mathrm{~cm}$ (site 10) to $26 \mathrm{~cm}$ (site 8).

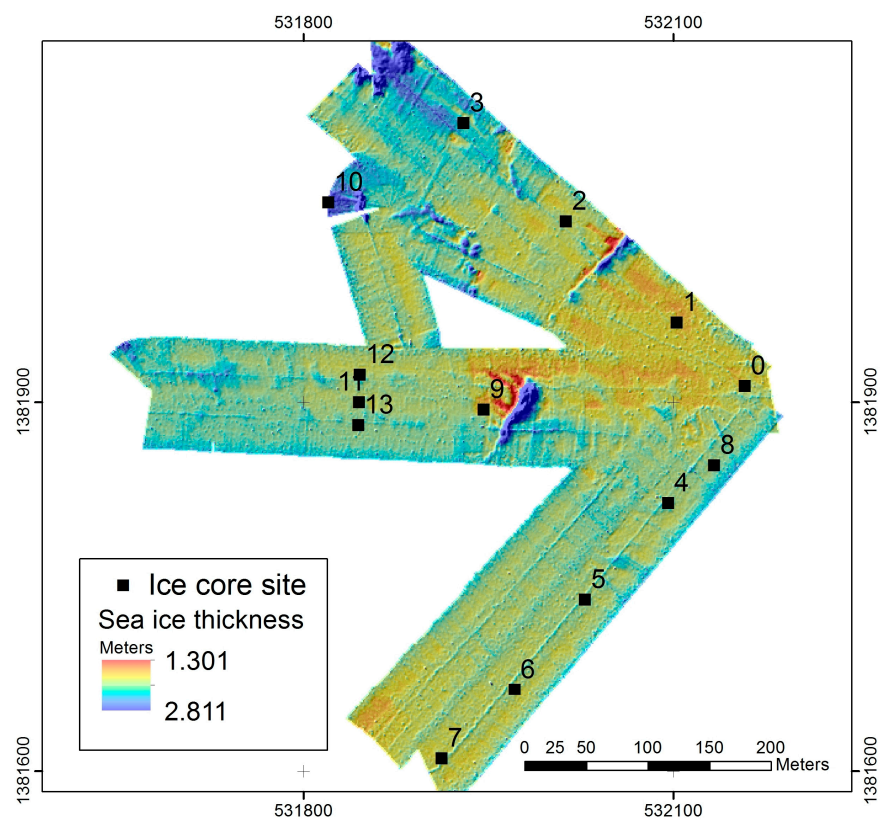

Figure 8. Map showing the location of ice cores sampled across the site at Cape Evans.

Table 1. Comparison of the pressure sensor depth results with the ice core depth by difference and $\%$ difference.

\begin{tabular}{ccccc}
\hline Core ID & $\begin{array}{c}\text { Pressure Sensor } \\
\text { Depth }(\mathbf{m})\end{array}$ & $\begin{array}{c}\text { Ice Core } \\
\text { Depth }(\mathbf{m})\end{array}$ & $\begin{array}{c}\text { Difference } \\
(\mathbf{m})\end{array}$ & $\begin{array}{c}\text { \% Difference of } \\
\text { Ice Thickness }\end{array}$ \\
\hline 0 & -1.636 & -1.880 & -0.244 & 14.91 \\
1 & -1.644 & -1.890 & -0.246 & 14.96 \\
2 & -1.660 & -1.880 & -0.220 & 13.25 \\
3 & -1.767 & -1.880 & -0.113 & 6.40 \\
4 & -1.751 & -1.890 & -0.139 & 7.94 \\
5 & -1.704 & -1.910 & -0.206 & 12.09 \\
6 & -1.663 & -1.910 & -0.247 & 14.85 \\
7 & -1.637 & -1.880 & -0.243 & 14.84 \\
8 & -1.679 & -1.940 & -0.261 & 15.54 \\
9 & -1.599 & -1.730 & -0.131 & 8.19 \\
10 & -1.912 & -1.930 & -0.018 & 0.94 \\
11 & -1.670 & -1.870 & -0.200 & 11.98 \\
12 & -1.674 & -1.870 & -0.196 & 11.71 \\
13 & -1.689 & -1.870 & -0.181 & 10.72 \\
\hline
\end{tabular}

Some of the differences in the sea ice thickness measurements between the core result and the pressure depth sensor result may have been due to platelet ice breaking off the bottom of the ice core as it was pulled to the surface. We estimate the length of the platelet ice to be in the order of 10-15 cm. A second explanation could be the averaging of the depths to the $1 \mathrm{~m}$ grid-comparing this to a $90 \mathrm{~mm}$ core width may account for some of the differences. Overall, the average difference between the two methods was $11.31 \mathrm{~cm}$ and the average thickness of the sea ice in this region was $1.6 \mathrm{~m}$ over the 12.42 ha area. 


\subsubsection{Sea Ice Slope}

Slope (Figure 6b) of the sea ice surface was calculated using the Horn [35] algorithm in ArcGIS (v10.2.1). The greatest slope was 23 degrees measured on transect (b), represented by the large ice keel in the center of the survey line. The ice keel is $\sim 72 \mathrm{~m}$ in length by $42 \mathrm{~m}$ in width. On the end of survey line A, smaller ice keels were also noted that presented slopes up to 20 degrees.

\subsubsection{Terrain Roughness or Vector Ruggedness Measure (VRM)}

Terrain roughness measures terrain ruggedness, or rugosity. It is calculated as the variation in three-dimensional orientation of grid cells within a neighborhood. Vector analysis is used to calculate the dispersion of vectors normal (orthogonal) to grid cells within the specified neighborhood. In this example, the neighborhood is $3 \times 3$ cells or $3 \mathrm{~m}$ ( $1 \mathrm{~m}$ grid resolution). This method effectively captures variability in slope and aspect into a single measure. Ruggedness values in the output raster can range from 0 (no terrain variation: Low) to 1 (complete terrain variation: High). Typical values for natural terrains range between 0 and about 0.4 . The terrain ruggedness results for this survey region ranged between 0.01 (very smooth) and 0.6 (indicative of the ice keel (Figure 9a) and the undulations in the ice measured over 1-2 m scales (Figure 9b).
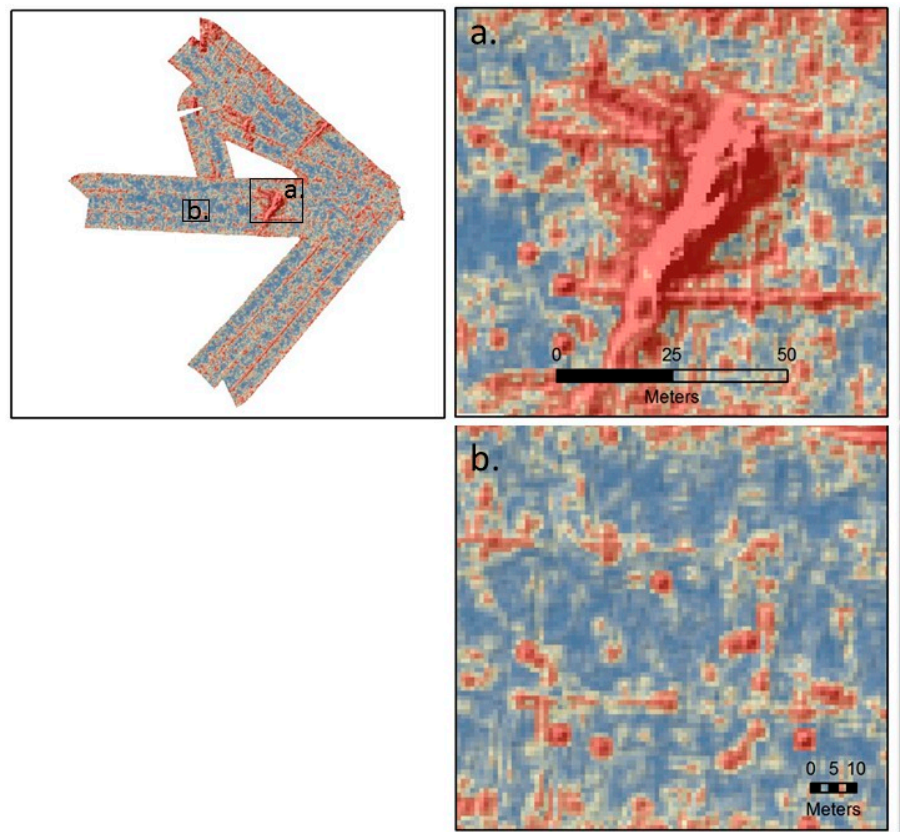
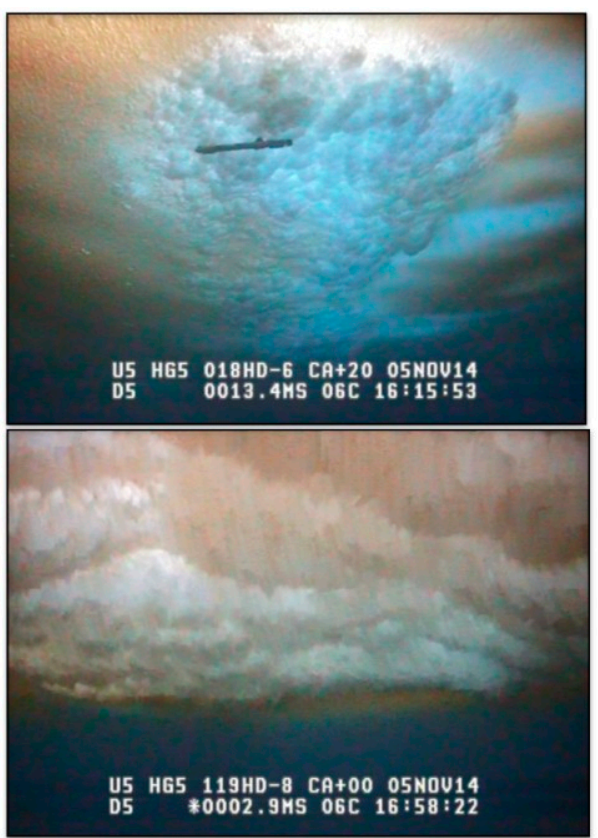

Figure 9. Sea ice ruggedness estimates showing (a) an ice keel (2-3 m thick); and (b) undulations in the ice surface (1-2 $\mathrm{m}$ in length scale). Validation imagery collected with a remotely operated vehicle (ROV) show the pressure keel from below and an example of the undulations in this location.

\subsection{Sea Ice Texture}

Due to the high density of pings produced by the interferometric system, the acoustic backscatter can be resolved at a very high resolution. When the backscatter is processed to the same resolution as the bathymetry $(1 \mathrm{~m})$ very fine scale features on the underside of the sea ice surface are not able to be resolved (Figure 10a). At $5 \mathrm{~cm}$ resolution, particular features such as "brine drainage channels" can be identified (Figure 10b) and (Figure 11a). These features are referred to as "broad scale" features because they occur across the surface at broad scales of 10-100 m, although the features themselves are only at a scale of $20 \mathrm{~cm}$ to $1 \mathrm{~m}$. The platelet ice that forms on the underside of the sea ice also has a unique backscatter signature (Figure 11b). These features can be identified in both the bathymetry at $1 \mathrm{~m}$ (as shown by the ice keel in Figure 9a) or in the backscatter imagery. 

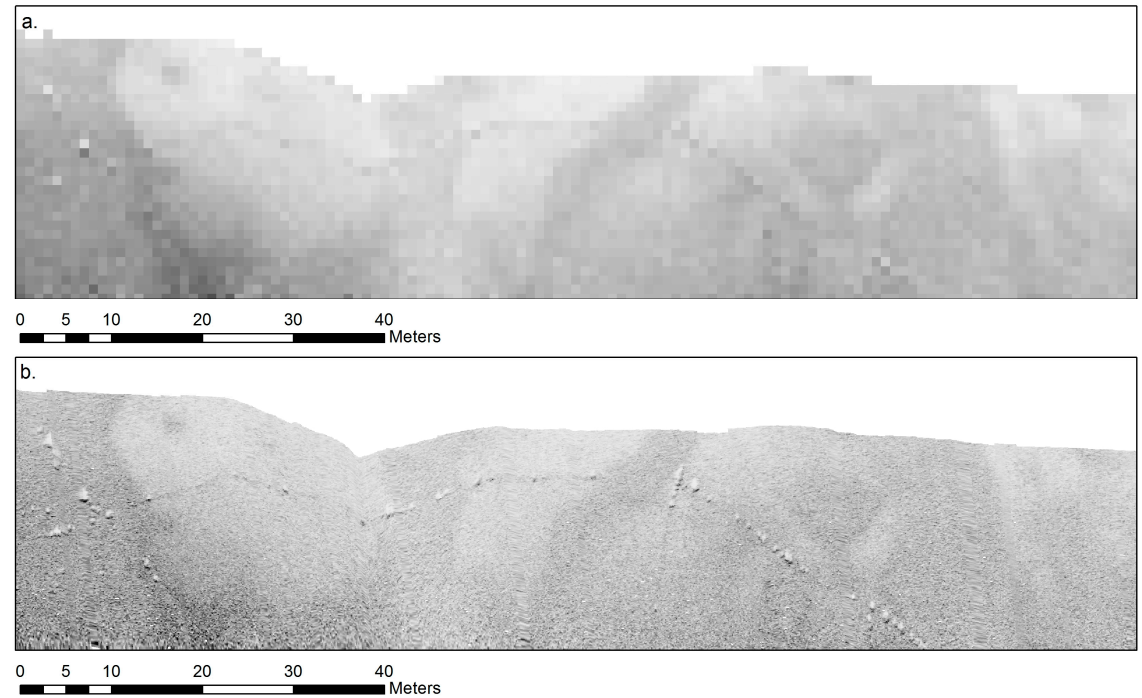

Figure 10. Comparison in backscatter resolution (a) $1 \mathrm{~m}$ resolution and (b) $5 \mathrm{~cm}$ resolution. The fine scale brine drainage channels are not clearly visible at $1 \mathrm{~m}$ resolution, but when the data is presented at $5 \mathrm{~cm}$ resolution the brine drainage channels can be clearly identified.

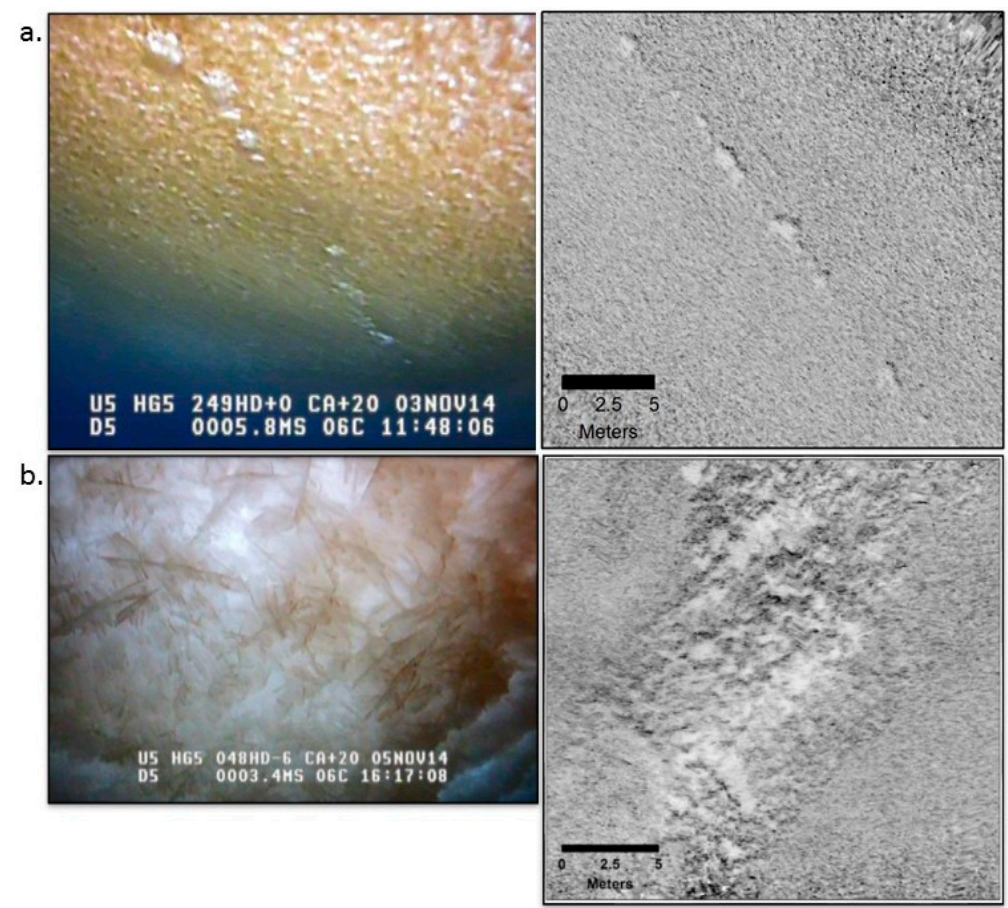

Figure 11. Broad scale textural features identified in the backscatter imagery processed at $5 \mathrm{~cm}$; (a) shows the texture of the brine drainage channels and (b) shows the texture of the ice keel.

Fine-scale ice habitats such as the boundaries between platelet ice and smooth ice are only able to be resolved by the fine-scale $5 \mathrm{~cm}$ backscatter imagery. The $1 \mathrm{~m}$ bathymetric surfaces are unable to resolve the platelet ice surfaces. The platelet ice that was mapped on the underside of the sea ice in the Ross Sea during this survey in November 2014 had a vertical length of $\sim 15 \mathrm{~cm}$ (Figure 12) and was patchy in its distribution over scales of $10 \mathrm{~s}$ of meters.

The range of the intensity values in the backscatter data ranged from 3 to $49 \mathrm{~dB}$. The difference in $\mathrm{dB}$ between the smooth ice and the platelet ice was $10 \mathrm{~dB}$. This would indicate that the roughness of the surface created by the platelet ice (at $5 \mathrm{~cm}$ resolution) was detectable by a quantifiable textural signature. 

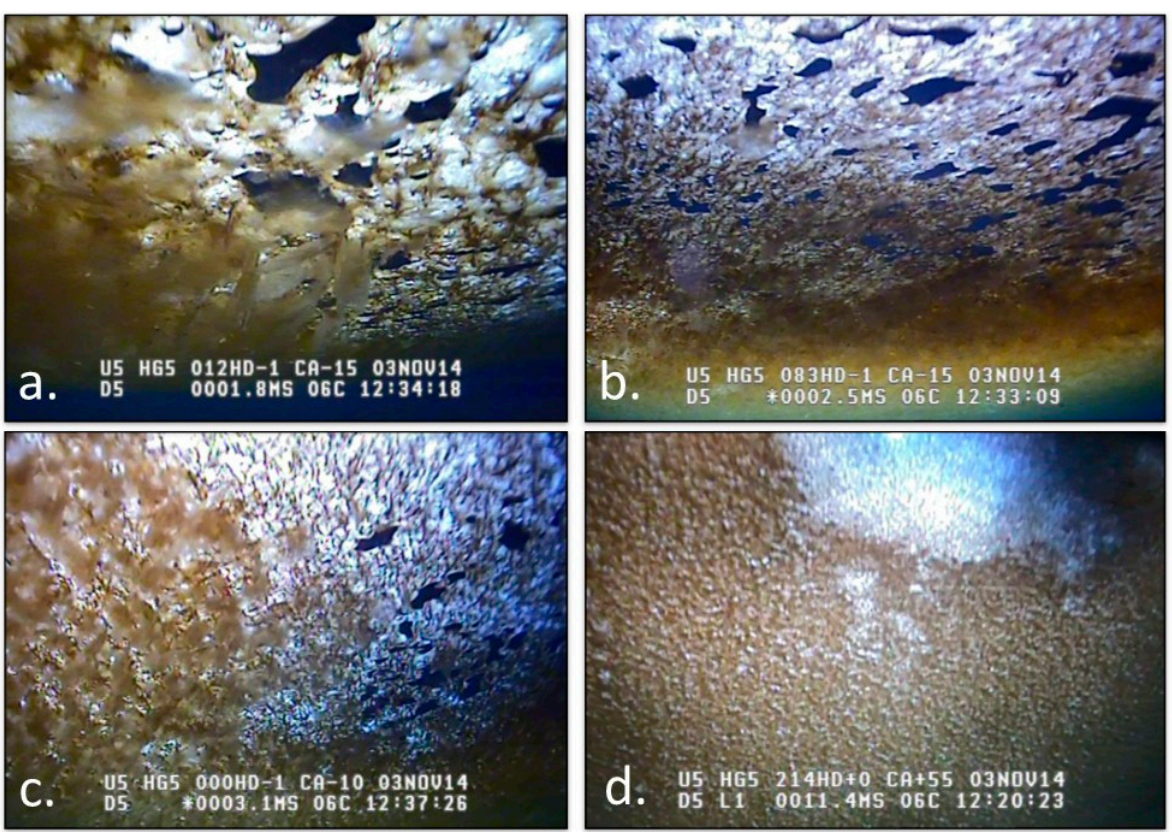

Figure 12. Example of the fine-scale ice textures identified in the ROV imagery; (a) boundary of platelet ice and smooth ice (close up); (b) smooth ice and platelet ice boundary from oblique view; (c) bottom-up view of platelet and smooth ice boundary; and (d) broadscale view of platelet and smooth ice.

The segmentation algorithm identified homogeneous regions across the backscatter surface (Figure 13a). Using an unsupervised $k$-means clustering algorithm, the textural statistics were effective in separating the boundaries between the platelet ice and the smooth ice regions. The statistical differences in dB between the classes is shown in Table 2 and Figure 13b. Overall, 1266 segments were created with a range of segment sizes $\left(\mathrm{m}^{2}\right)$ from $12 \mathrm{~m}^{2}$ to $400 \mathrm{~m}^{2}$ (Mean: $97.92 \mathrm{~m}^{2}$, standard deviation: $117.18 \mathrm{~m}^{2}$ ). Figure 13 shows the classified area only on a small region so that subtle differences in the backscatter can be clearly seen (zoomed in).
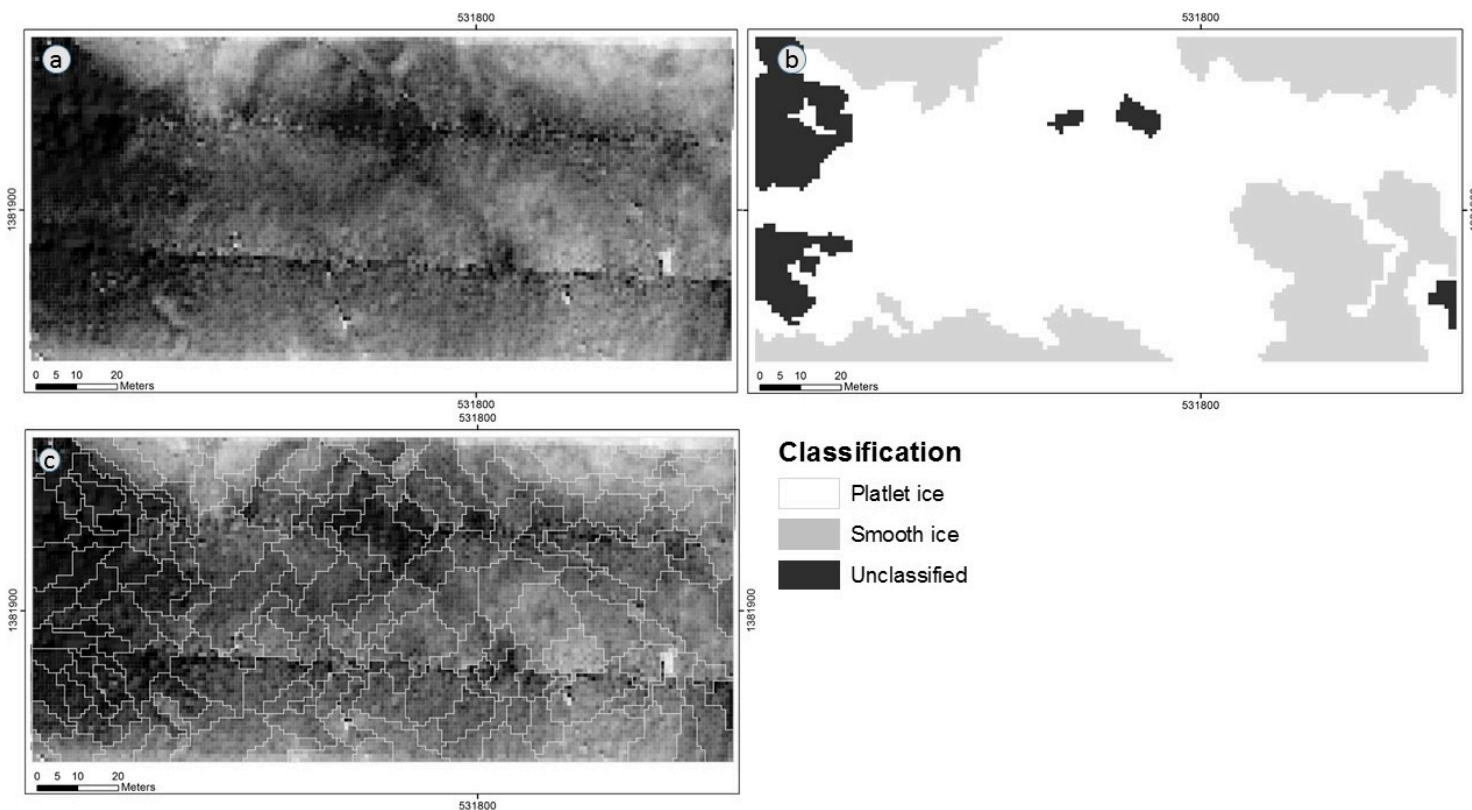

\section{Classification}

Platlet ice

Smooth ice

Unclassified

Figure 13. (a) Acoustic backscatter image processed at $5 \mathrm{~cm}$ resolution; (b) segmentation of the backscatter based on spectral statistics as outlined in Table 2; (c) classification of the ice surface into three classes platelet ice, smooth ice and unclassified. 
Table 2. Values of class cluster centers, within-cluster sum of squares and cluster sizes and data mean for each of the statistics generated.

\begin{tabular}{ccccccccc}
\hline Class & $\begin{array}{c}\text { GLCM } \\
\text { Homogeneity }\end{array}$ & $\begin{array}{c}\text { GLCM } \\
\text { Std Dev }\end{array}$ & $\begin{array}{c}\text { GLCM } \\
\text { Dissimilarity }\end{array}$ & $\begin{array}{c}\text { GLCM } \\
\text { Mean }\end{array}$ & $\begin{array}{c}\text { dB } \\
\text { Mean }\end{array}$ & $\begin{array}{c}\text { dB Std } \\
\text { Dev }\end{array}$ & $\begin{array}{c}\text { Within Cluster } \\
\text { Sum of Squares }\end{array}$ & $\begin{array}{c}\text { Cluster } \\
\text { Sizes }\end{array}$ \\
\hline 1 Smooth ice & 0.028 & 0.751 & 0.629 & 0.437 & 10 & 6.7 & 5.82 & 168 \\
\hline 2 Platelet ice & 0.044 & 0.53 & 0.45 & 0.63 & 17.8 & 6 & 6.0 & 387 \\
\hline 3 Unclassifed & 0.09 & 0.33 & 0.30 & 0.75 & 29 & 7.3 & 6.5 & 331 \\
\hline
\end{tabular}

The $k$-means clustering algorithm assigns points to the nearest cluster by distance. The standard algorithm minimizes the within-cluster sum of squares (WCSS) and assigns by "least sum of squares", which is equivalent to assigning by the smallest Euclidean distance. The first two components in the discriminant analysis explain $91.23 \%$ of the variability in the textural analysis using the discriminant variables of GLCM homogeneity, GLCM contrast, GLCM standard deviation, GLCM dissimilarity, GLCM mean, backscatter intensity mean (dB), and standard deviation of dB (Figure 14).

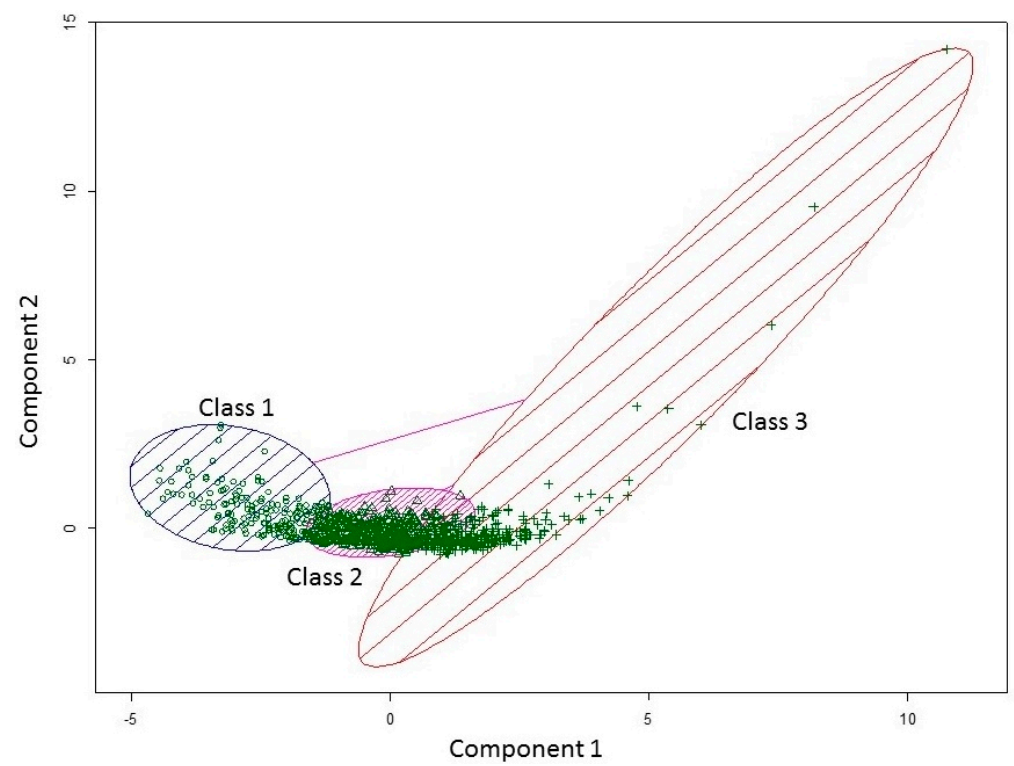

Figure 14. Discriminant analysis results Class 1-Smooth ice, Class 2-Platelet ice, and Class 3-Unclassified. These two components explain $91.23 \%$ of the point variability.

\section{Discussion}

The Gavia AUV was successfully used in this survey for mapping underneath the sea ice and characterizing different ice morphologies and ice textures. Although AUV platforms have been used to map under the sea ice in limited studies $[1,6]$ this research demonstrated the ability to conduct concise transects covering 12.42 hectares at very high spatial resolution $(5 \mathrm{~cm})$ and high degrees of precision ( $0.01 \mathrm{~m}$ drift) of this cryptic marine environment. Aside from mapping sea ice thickness we have uniquely resolved smooth ice from platelet ice at $5 \mathrm{~cm}$ resolution. This is an important and novel development in this field and has many implications for a variety of disciplines.

\subsection{Relevance of Spatial Data for Sea Ice Studies}

Different ice morphologies and textures are identified and described in this study. These fine scale features may prove useful to understanding sea ice processes, particularly fine-scale water flow direction over the ice/water boundary. The backscatter information from the high-resolution interferometric sonar shows fine-scale textural patterns which may also be useful to infer water circulation in the top part of the water column. 
It is well appreciated that sea ice supports a productive ecosystem, normally associated within brine drainage channels in the ice [9,36]. A variety of organisms are dependent on this concentrated localized food source for all or some of their lifecycles, including krill-a key component of Southern Ocean food chains [37]. While there is limited biological information that compares areas with and without platelet ice structures, what there is suggests that it is a distinctive and significant habitat, with a productive flora and a characteristic invertebrate and vertebrate fauna [22]. Its relatively open structure can be expected to allow more water exchange than brine channels, and yet still provide a localized nutrient cycling regime [21], a high surface area for colonization, and a degree of protection from predators. To our knowledge, this is the first successful attempt to map habitat complexity of sea ice, and allows stratified sampling strategies to be developed that will better quantify ecological processes over broad scales.

Addition of further sensor arrays on AUVs may further aid in the spatial quantification of sea ice communities which, like many other aspects of a sea ice study, is constrained by access. For the most part this access involves drilling ice cores, which are laborious, spatially limited, and, when substantial amounts of platelet ice are present, inherently inaccurate. Sea ice communities are, however, known to be variable on small and broad spatial and temporal scales [38,39], but techniques to quantify this variability and to relate it to driving variables are poorly developed. Recently there have been examples of the use of remote operated vehicles and under-ice sleds to examine sea ice properties [38,40], but to date these have been limited to ice floe-scale investigations. In this study it appears that resolving the data to a scale of $1 \mathrm{~m}$ permitted the spatial mapping of features that represented spatial complexity. By adding other ecologically relevant sensors, such as optical arrays that can estimate algal pigment concentrations [40], an improved capacity to related physical habitat to biological communities may emerge.

\subsection{Data Processing Future Recommendations}

The processing workflows uniquely developed for this project show that it is possible to process Geoswath Plus data using an inverted configuration in CARIS. However, there are still opportunities to improve these processing methods and potentially increase the resolution that the bathymetric data can be resolved to. The ability to use a single CARIS project and HVF to process both bathymetry and backscatter data would greatly simplify this workflow. This would involve exploring methods to invert the imagery and depths simultaneously that also result in the correct orientation for correcting for AUV depth. An investigation would be warranted to look at options for doing this during the data acquisition phase. Another option may be importing the data without the pressure depth values and only the 180 degree gyro error and then manually applying inverted pressure depths using a tide or delta draft file to correct for AUV depth.

The issue with the Gavia SEANAV INS depth values being recorded as "Heave" should be further investigated in future surveys. It is possible that this needs to be set as 0 in the acquisition software so that it is not automatically applied to the data. Using the workflow outlined in Figure 3 resulted in a surface representing the ice thickness below sea level. This does not take into account the thickness of the sea ice that could be floating above sea level due to the buoyancy of the ice.

As the technology for AUV payloads improves [41], software architecture will be required to be more open and flexible to be able to account for the particular moving platform (i.e., AUV, UAV, or drone) that surveying equipment can be carried upon. This research highlights the excellent capacity of CARIS (Teledyne CARIS, Fredericton, NB, Canada) to be modified and adapted to process this acoustic data through developing a novel and accurate workflow.

\section{Conclusions}

The study reveals how the application of traditional high-resolution seafloor mapping systems can be used to capture information on the variability of the underside of a sea ice environment. In the Antarctic, sea ice is expected to undergo much spatial and temporal variation due to the impacts of 
climate change. Methodologies such as those described here provide the potential for new pathways to capture data in these unique and harsh environments that have previously been too challenging to survey. Considering the recent cutting-edge underwater technology investments around the world, and the increasing range of environments that they are being sent to sample in, new methods for acoustic processing that can resolve spatial information with high accuracies and georeferenced precision are fundamental. Methods that extend traditional downward-looking seafloor mapping technologies will be imperative for a wider range of applications where the instrument can collect data in underwater environments with full 360 degree rotational payload to map ice walls of glaciers or under ice shelves. The range of applications in the cryosphere-ocean interface is only just beginning to be realized.

Acknowledgments: The authors are grateful for the financial support of the New Zealand Antarctic Research Institute through grant NZARI-2014-3, and for logistics provided by Antarctica New Zealand. Lucieer and Forrest were supported under the Australian Research Council's Special Research Initiative for Antarctic Gateway Partnership (Project ID SR140300001). The CARIS Help Desk provided invaluable help and guidance in developing new processing procedures using CARIS. The authors wish to acknowledge the Australian Defense Science and Technology Group (DSTG) for the loan of the Geoswath Plus, the other members of K081; L. Chresten Lund Hansen, B. Sorrell and R. Cossu for their field assistance and the staff at Scott Base for their professional support with logistics that ensured the success of this project. The authors are grateful to the four reviewers who substantially improved this manuscript.

Author Contributions: V.L., A.L.F. and I.H. conceived and designed the acoustic sampling experiments; V.L. and A.L.F. performed the experiments; V.L. and A.W.N. analyzed the data; V.L. performed the spatial and textural analysis, V.L., A.W.N., A.L.F. and I.H. wrote the paper.

Conflicts of Interest: The authors declare no conflict of interest.

\section{References}

1. Cadena, A. Design and implementation of cooperative autonomous underwater vehicles for antarctic exploration. Proc. SPIE 2011. [CrossRef]

2. Doble, M.J.; Skourup, H.; Wadhams, P.; Geiger, C.A. The relation between Arctic sea ice surface elevation and draft: A case study using coincident AUV sonar and airborne scanning laser. J. Geophys. Res. Oceans 2011, 116. [CrossRef]

3. Dowdeswell, J.A.; Evans, J.; Mugford, R.; Griffiths, G.; McPhail, S.; Millard, N.; Stevenson, P.; Brandon, M.A.; Banks, C.; Heywood, K.J.; et al. Instruments and methods autonomous underwater vehicles (AUVs) and investigations of the ice; ocean interface in Antarctic and Arctic waters. J. Glaciol. 2008, 54, 661-672. [CrossRef]

4. Ferguson, J. Under-ice seabed mapping with AUVs. In Proceedings of the OCEANS 2009-EUROPE, Bremen, Germany, 11-14 May 2009.

5. Nicholls, K.W.; Abrahamsen, E.P.; Buck, J.J.H.; Dodd, P.A.; Goldblatt, C.; Griffiths, G.; Heywood, K.J.; Hughes, N.E.; Kaletzky, A.; Lane-Serff, G.F.; et al. Measurements beneath an Antarctic ice shelf using an autonomous underwater vehicle. Geophys. Res. Lett. 2006, 33. [CrossRef]

6. Williams, G.; Maksym, T.; Wilkinson, J.; Kunz, C.; Murphy, C.; Kimball, P.; Singh, H. Thick and deformed Antarctic sea ice mapped with autonomous underwater vehicles. Nat. Geosci. 2014, 8, 61-67. [CrossRef]

7. Liu, C.; Chao, J.; Gu, W.; Li, L.; Xu, Y. On the surface roughness characteristics of the land fast sea-ice in the Bohai Sea. Acta Oceanol. Sin. 2014, 33, 97-106. [CrossRef]

8. Tschudi, M.; Fowler, C.; Maslanik, J.; Stroeve, J. Tracking the movement and changing surface characteristics of Arctic sea ice. IEEE J. Appl. Earth Obs. Remote Sens. 2010, 3, 536-540. [CrossRef]

9. McMinn, A.; Martin, A.; Ryan, K. Phytoplankton and sea ice algal biomass and physiology during the transition between winter and spring (McMurdo Sound, Antarctica). Pol. Biol. 2010, 33, 1547-1556. [CrossRef]

10. Arrigo, K.R.; Thomas, D.N. Large scale importance of sea ice biology in the Southern Ocean. Antarct. Sci. 2004, 16, 471-486. [CrossRef]

11. Thomas, D.; Dieckmann, G. Antarctic sea ice-A habitat for extremophiles. Science 2002, 295, 641-644. [CrossRef] [PubMed]

12. Lizotte, M.P. The contributions of sea ice algae to Antarctic marine primary production. Am. Zool. 2001, 41, 57-73. [CrossRef] 
13. Fernández-Méndez, M.; Katlein, C.; Rabe, B.; Nicolaus, M.; Peeken, I.; Bakker, K.; Flores, H.; Boetius, A. Photosynthetic production in the central Arctic Ocean during the record sea-ice minimum in 2012. Biogeosciences 2015, 12, 3525-3549. [CrossRef]

14. Jeffries, M.O.; Schwartz, K.; Morris, K.; Veazey, A.D.; Krouse, H.R.; Gushing, S. Evidence for platelet ice accretion in Arctic sea ice development. J. Geophys. Res. 1995, 100, 10905-10914. [CrossRef]

15. Langhorne, P.J.; Hughes, K.G.; Gough, A.J.; Smith, I.J.; Williams, M.J.M.; Robinson, N.J.; Stevens, C.L.; Rack, W.; Price, D.; Leonard, G.H.; et al. Observed platelet ice distributions in Antarctic sea ice: An index for ocean-ice shelf heat flux. Geophys. Res. Lett. 2015, 42, 5442-5451. [CrossRef]

16. Garrison, D.L.; Sullivan, C.W.; Ackley, S.F. Sea ice microbial community studies in the Antarctic. Bioscience 1986, 36, 243-250. [CrossRef]

17. Lazzara, L.; Nardello, I.; Gallo, C.; Mangoni, O.; Saggiomo, V. Light environment and seasonal dynamics of microalgae in the annual sea ice at Terra Nova Bay (Ross Sea, Antarctica). Antarct. Sci. 2007, 19, 83-92. [CrossRef]

18. Smith, I.J.; Langhorne, P.J.; Haskell, T.G.; Trodhal, H.J.; Frew, R.; Ross Vennell, M. Platelet ice and the land-fast sea ice of McMurdo Sound, Antarctica. Ann. Glaciol. 2001, 33, 21-27. [CrossRef]

19. Hoppmann, M.; Nicolaus, M.; Hunkeler, P.A.; Heil, P.; Behrens, L.K.; König-Langlo, G.; Gerdes, R. Seasonal evolution of an ice-shelf influenced fast-ice regime, derived from an autonomous thermistor chain. J. Geophys. Res. Oceans 2015, 120, 1703-1724. [CrossRef]

20. Hunkeler, P.A.; Hoppmann, M.; Hendricks, S.; Kalscheuer, T.; Gerdes, R. A glimpse beneath Antarctic sea ice: Platelet layer volume from multifrequency electromagnetic induction sounding. Geophys. Res. Lett. 2016, 43, 222-231. [CrossRef]

21. Schnack-Schiel, S.B.; Dieckman, G.S.; Kattner, G.; Thomas, D.N. Copepods in summer platelet ice in the eastern Weddell Sea, Antarctica. Pol. Biol. 2004, 27, 502-506. [CrossRef]

22. Vacchi, M.; DeVries, A.L.; Evans, C.W.; Bottaro, M.; Ghigliotti, L.; Cutroneo, L.; Pisano, E. A nursery area for the Antarctic silverfish Pleuragramma antarcticum at Terra Nova Bay (Ross Sea): First estimate of distribution and abundance of eggs and larvae under the seasonal sea-ice. Pol. Biol. 2012, 35, 1573-1585. [CrossRef]

23. La Mesa, M.; Eastman, J.T.; Vacchi, M. The role of notothenioid fish in the food web of the Ross Sea shelf waters: A review. Pol. Biol. 2004, 27, 321-338. [CrossRef]

24. Mangoni, O.; Saggiomo, M.; Modigh, M.; Catalano, G.; Zingone, A.; Saggiomo, V. The role of platelet ice microalgae in seeding phytoplankton blooms in Terra Nova Bay (Ross Sea, Antarctica): A mesocosm experiment. Pol. Biol. 2009, 32, 311-323. [CrossRef]

25. Mundy, C.J.; Ehn, J.K.; Barber, D.G.; Michel, C. Influence of snow cover and algae on the spectral dependence of transmitted irradiance through Arctic landfast first-year sea ice. J. Geophys. Res. Oceans 2007, 112. [CrossRef]

26. Katlein, C.; Arndt, S.; Nicolaus, M.; Perovich, D.K.; Jakuba, M.V.; Suman, S.; Elliott, S.; Whitcomb, L.L.; McFarland, C.J.; Gerdes, R.; et al. Influence of ice thickness and surface properties on light transmission through Arctic sea ice. J. Geophys. Res. Oceans 2015, 120, 5932-5944. [CrossRef] [PubMed]

27. Nolan, M.; Larsen, C.; Sturm, M. Mapping snow depth from manned aircraft on landscape scales at centimeter resolution using structure-from-motion photogrammetry. Cryosphere 2015, 9, 1445-1463. [CrossRef]

28. Jenkins, A.; Dutrieux, P.; Jacobs, S.S.; McPhail, S.D.; Perrett, J.R.; Webb, A.T.; White, D. Observations beneath Pine Island Glacier in West Antarctica and implications for its retreat. Nat. Geosci. 2010, 3, 468-472. [CrossRef]

29. Hayes, D.R.; Morison, J. Ice- ocean turbulent exchange in the Arctic summer measured by an autonomous underwater vechile. Limnol. Oceanogr. 2008, 53, 2287-2308. [CrossRef]

30. Doble, M.J.; Forrest, A.L.; Wadhams, P.; Laval, B.E. Through-ice AUV deployment: Operational and technical experience from two seasons of Arctic fieldwork. Cold Reg. Sci. Technol. 2009, 56, 90-97. [CrossRef]

31. Kukulya, A.; Plueddemann, A.; Austin, T.; Stokey, R.; Purcell, M.; Allen, B.; Littlefield, R.; Freitag, L.; Koski, P.; Gallimore, E.; et al. Under-ice operations with a REMUS-100 AUV in the Arctic. In Proceedings of the IEEE/OES Autonomous Underwater Vehicles (AUV), Monterey, CA, USA, 1-3 Septemebr 2010.

32. Schmidt, V.; Raineault, N.A.; Skarke, A.; Trembanis, A.; Mayer, L.A. Correction of bathymetric survey artifacts resulting from apparent wave-induced vertical position of an AUV. In Proceedings of the Canadian Hydrographic Conference (CHC), Quebec City, QC, Canada, 21-23 June 2010. 
33. Lucieer, V.; Hill, N.A.; Barrett, N.S.; Nichol, S. Do marine substrates 'look' and 'sound' the same? Supervised classification of multibeam acoustic data using autonomous underwater vehicle images. Estuar. Coast. Shelf Sci. 2013, 117, 94-106. [CrossRef]

34. Lucieer, V.L. The Application of Automated Segmentation Methods and Fragementation Statistics to Characterise Rocky Reef Habitat. J. Spat. Sci. 2007, 52, 81-91. [CrossRef]

35. Horn, B. Hill shading and the reflectance map. Proc. IEEE 1981, 69, 14-47. [CrossRef]

36. Mock, T.; Thomas, D.N. Recent advances in sea-ice microbiology. Environ. Microbiol. 2005, 7, 605-619. [CrossRef] [PubMed]

37. Nicol, S. Krill, currents, and sea ice: Euphausia superba and its changing environment. Bioscience 2006, 56, 111-120. [CrossRef]

38. Nicolaus, M.; Katlein, C.; Maslanik, J.; Hendricks, S. Changes in Arctic sea ice result in increasing light transmittance and absorption. Geophys. Res. Lett. 2012, 39. [CrossRef]

39. Rysgaard, S.; Kühl, M.; Glud, R.; Hansen, J. Biomass, production and horizontal patchiness of sea ice algae in a high-Arctic fjord (Young Sound, NE Greenland). Mar. Ecol. Prog. Ser. 2001, 223, 15-26. [CrossRef]

40. Nicolaus, M.; Katlein, C. Mapping radiation transfer through sea ice using a remotely operated vehicle (ROV). Cryosphere 2013, 7, 763-777. [CrossRef]

41. Lucieer, V.L.; Forrest, A.L. Emerging Mapping Techniques for Autonomous Underwater Vehicles (AUVs). In Seafloor Mapping along Continental Shelves; Springer: New York, NY, USA, 2016; pp. 53-67.

(C) 2016 by the authors; licensee MDPI, Basel, Switzerland. This article is an open access article distributed under the terms and conditions of the Creative Commons Attribution (CC-BY) license (http://creativecommons.org/licenses/by/4.0/). 